\title{
RHEOLOGICAL PROPERTIES OF ACRYLIC BONE CEMENT SmartSet ${ }^{\circledR}$ HV
}

The rheological behaviour of polymethylmethacrylate bone cement SmartSet ${ }^{\circledR} H V$ prepared by hand and vacuum mixing was characterized using an oscillatory rheometer. Complex viscosity, damping factor, loss and storage modulus were measured by dynamic mechanical thermal analysis (DMTA) after several periods of ageing as a function of temperature for a range of 22-70 ${ }^{\circ} \mathrm{C}$. Time-dependent changes of measured parameters were observed which were partially influenced by the cement preparation method.

\section{Introduction}

Acrylic bone cements are commonly used in orthopaedric surgery as bone filler and implant fixture agents. They are twocomponent systems consisting of powdered polymer and liquid monomer which are mixed together to form a dough.

Bone cement was mixed first using a spatula and opened bowl. During this method the person who mixed the cement was exposed to a high level of methylmethacrylate (MMA) vapors which are noxious. Moreover, mixing at atmospheric pressure in an opened bowl caused high degree of porosity of the premix and also of the cured cement. Nowadays, cement is mixed and transferred within the closed mixing barrel under reduced pressure (vacuum), thus there is no human contact with it. Vacuum mixing improves the quality of cement by eliminating the quantity of air bubbles in the cement structure and also reduces the level of monomer fumes discharged into environment [1]. Carefully prepared and cleaned bone canal is filled with the polymerizing cement mass and then the prosthesis is inserted and held in place while the cement solidifies [2]. The solidification is caused by exothermic polymerization of the monomer included in the liquid component. During this process free radicals break the covalent double bonds between the carbons of monomer allowing them to bind to the lengthening polymer chains. The function of cured bone cement in vivo is load and stress distribution by mechanical bonding between the bone and endoprosthesis [3].

During the last years, numbers of investigations attended to rheological properties of bone cements were realized. But no one of them was aimed at time-dependent changes which occur after bone cement ageing concerning cement preparation technology. Because of this reason we focused our attention to these questions and realized mechanical thermal analyses (DMTA) on aged cements which were prepared by different techniques of mixing (hand mixing, vacuum mixing).

\section{Background to rheological characterization}

A viscoelastic material, as the name implies, exhibits both viscous and elastic properties. These materials change their properties with temperature and time. One way to look at these changes is by measuring the response of the material to deformation by periodic forces (during forced vibration or small-amplitude oscillatory shear) [4]. The response obtained shows that stress and strain are not in phase, the strain delays behind the stress by a phase angle. If the oscillatory shear is sinusoidal, then shear stress is equal to

$$
\tau(t)=\tau_{0} \cdot e^{i \omega t}=\tau_{0}(\cos \omega t+i \cdot \sin \omega t)
$$

where $\tau_{0}$ - stress amplitude, $\omega$ - angular frequency, $t$ - time and $i=\sqrt{-1}$.

Because of the delay shear strain is then equal to

$$
\gamma(t)=\gamma_{0} \cdot e^{i(\omega t-\delta)}=\gamma_{0}(\cos (\omega t-\delta)+i \cdot \sin (\omega t-\delta))
$$

where $\gamma_{0}$ - strain amplitude and $\delta$ - phase angle.

The complex shear modulus $G^{*}$ is defined as

$$
G^{*}=\frac{\tau(t)}{\gamma(t)}
$$

Using equation (1) and (2), it can be devided into two parts

$$
G^{*}=G^{\prime}+i \cdot G^{\prime \prime}=\frac{\tau_{0}}{\gamma_{0}}(\cos \delta+i \cdot \sin \delta)
$$

\footnotetext{
* Henrietta Lelovics, Tatiana Liptakova

Department of Materials Engineering, Faculty of Mechanical Engineering, University of Zilina, Slovakia, E-mail: henrietta.lelovics@fstroj.uniza.sk
} 
The first $G^{\prime}$ is in phase with strain, and the second $G^{\prime \prime}$ is out of phase with strain with angle $\delta$. Therefore, two dynamic moduli can be defined as

$$
G^{\prime}=\frac{\tau_{0}}{\gamma_{0}} \cos \delta \text { and } G^{\prime \prime}=\frac{\tau_{0}}{\gamma_{0}} \sin \delta
$$

$G^{\prime}$ is called storage modulus and $G^{\prime \prime}$ is called loss modulus. The $G^{\prime}$ value is a measure of the deformation energy stored by the sample during the shear process. Thus, it represents the elastic behaviour. $G^{\prime \prime}$ value is a measure of the deformation energy used up by the sample during the shear process and therefore it represents the viscous behaviour of the material [5, 6]. From equations (2) - (6) it can be seen that

$$
\operatorname{tg} \delta=\frac{G^{\prime \prime}}{G^{\prime}}
$$

which is also called damping factor [7]. It reveals the ratio of the viscous and the elastic portion of the viscoelastic deformation behaviour. Idealelastic behaviour is specified in term of $\delta=0^{\circ}$ as $\operatorname{tg} \delta=0$ and the idealviscous behaviour can be expressed by $\delta=90^{\circ}$ as $\operatorname{tg} \delta=\infty$.

The complex viscosity $\eta^{*}$ is defined by the equation

$$
\eta^{*}=\frac{\tau(t)}{\dot{\gamma}(t)}
$$

where $\dot{\gamma}$ is shear rate. Thus, complex viscosity can be also written as

$$
\left|\eta^{*}\right|=\frac{\left|G^{*}\right|}{\omega}
$$

\section{Experimental material}

As an experimental material acrylic self-curing high viscosity bone cement SmartSet $\mathrm{HV}^{\circledR}$ was used. It is suitable for hand and vacuum mixing as well and its quantitative composition is specified below in Table 1.

The powdered component is white coloured and consists mainly of a methylmethacrylate (MMA) and methylacrylate (MA) based polymer. It also contains di-benzoyl peroxide which initiates cement polymerization when the powder and liquid components are premixed and radiopaque agent zirconium dioxide.

The liquid component is colorless and flammable with a distinctive odor. Its major component is the monomer methylmethacrylate (MMA). Hydroquinone is added as a stabilizer preventing pre- mature polymerization which may occur when the liquid is exposed to heat or light. N,N-dimethyl-p-toluidine promotes cement polymerization.

\section{Specimen preparation}

Cement specimens were prepared by hand and vacuum mixing technique, both with exact timing. For hand mixing a suitable ceramic mixing bowl and spatula were used. The powdered component was poured into a bowl and then liquid component was added. The dough was mixed for 30 seconds very carefully. When the dough was formed there was a need to wait 60 seconds (waiting time) for this type of cement. Then it was taken into hands and kneaded for a few seconds. For vacuum mixing the CEMVAC syringe mixing system was used. After 90 seconds of mixing the syringe system with included cement was transferred into a suitable application gun from where the cement mass was ready to strike out.

After mixing processes the cement was stroked into a metal mould with a length of $50 \mathrm{~mm}$ and cross section $2 \times 8 \mathrm{~mm}$ where it hardened for about 15 minutes. Then, hardened specimens were removed form the mould and stored on air at $25{ }^{\circ} \mathrm{C}$ and at relative humidity of $40-45 \%$ for 3, 6 and 12 months.

\section{Experimental methods}

Experimental data were obtained by using an oscillatory rheometer Physica MCR301 with a convection heating device CTD 450. In dynamic mechanical thermal analysis (DMTA) under torsion, the physical properties of the samples were measured as a function of the temperature. The magnitude of the oscillating stress was kept as small as possible so that the cements structure was not destroyed or changed during the measurement. The measuring cell CTD 450 enables gradient-free measurement of the material properties according to the standard ASTM D-5279 [8]. The temperature displayed by the sensor corresponds to the actual sample temperature at all times. The main advantage of this measuring method is in simultaneous monitoring of all mentioned parameters, e.g. $G^{\prime}, G^{\prime \prime}$, $\operatorname{tg} \delta$ and $\eta^{*}$.

\section{Results and discussion}

Our measurements on the oscillatory rheometer Physica MCR301 were performed under constant dynamical mechanical

Quantitative composition of bone cement SmartSet ${ }^{\circledR} \mathrm{HV}$

\begin{tabular}{|c|c|c|c|c|c|}
\hline \multicolumn{2}{|c|}{ Bone Cement Powder } & \multicolumn{3}{c|}{ Bone Cement Liquid } \\
\hline MMA/MA copolymer & Di-benzoyl peroxide & Zirconium dioxide & MMA & $\begin{array}{c}\text { N,N-dimethyl-p- } \\
\text { toluidine }\end{array}$ & Hydroquinone \\
\hline $84(\% \mathrm{w} / \mathrm{w})$ & $1(\% \mathrm{w} / \mathrm{w})$ & $15(\% \mathrm{w} / \mathrm{w})$ & $97.5(\% \mathrm{w} / \mathrm{w})$ & $\leq 2.5(\% \mathrm{w} / \mathrm{w})$ & $0.0075(\% \mathrm{w} / \mathrm{w})$ \\
\hline
\end{tabular}


conditions. Deformation amplitude $\gamma$ was $0.05 \%$ and frequency of oscillation $f$ was $1 \mathrm{~Hz}$, which practically isn't exceeded in vivo. The temperature range of measurements was between 25 and $75^{\circ} \mathrm{C}$. The lower limit of this interval represents the storage temperature

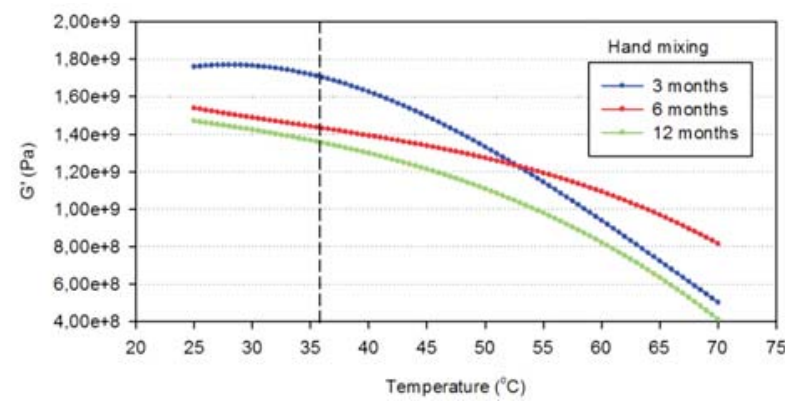

Fig. $1 G^{\prime}$ of hand-mixed samples

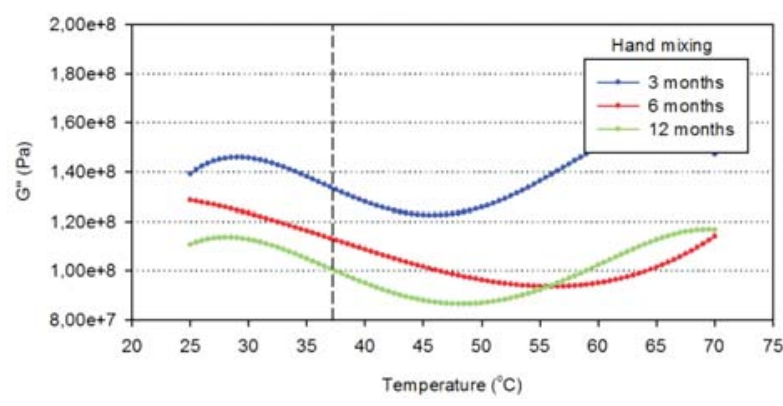

Fig. $3 G^{\prime \prime}$ of hand-mixed samples

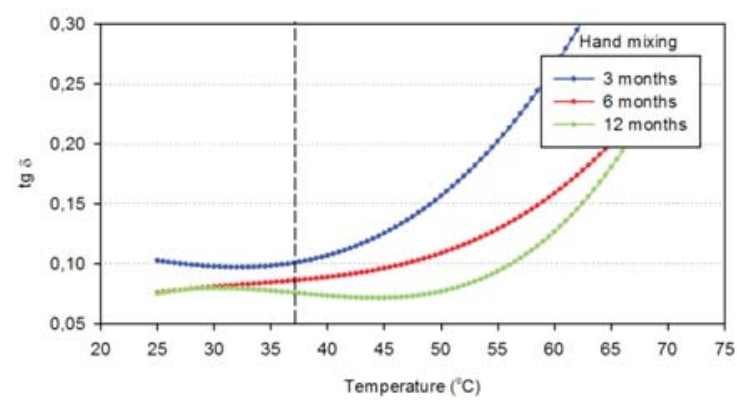

Fig. $5 \operatorname{tg} \delta$ of hand-mixed samples

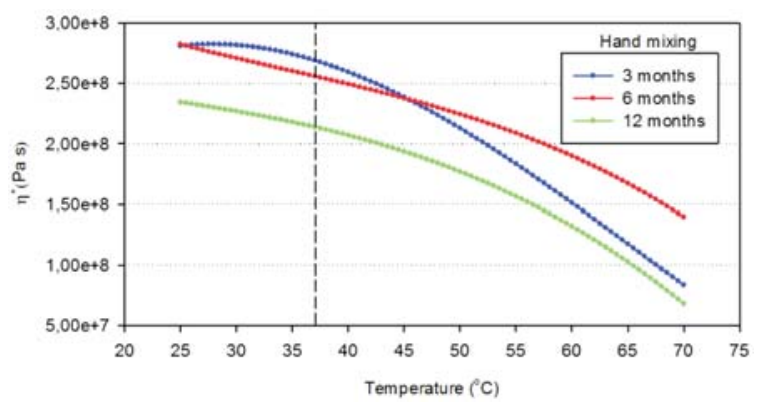

Fig. $7 \eta *$ of hand-mixed samples of specimens and the upper interval is under the glass transition temperature of polymethylmethacrylate (PMMA). Heating rate during the measurements was $2 \mathrm{~K} \mathrm{~min}^{-1}$ according to ISO 672110 [9].

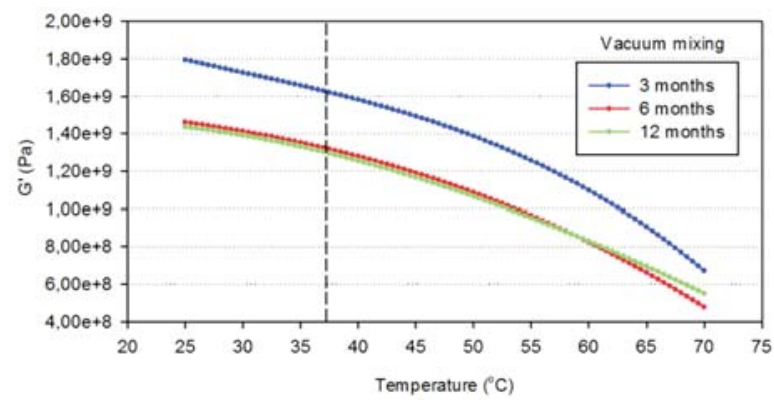

Fig. $2 G^{\prime}$ of vacuum-mixed samples

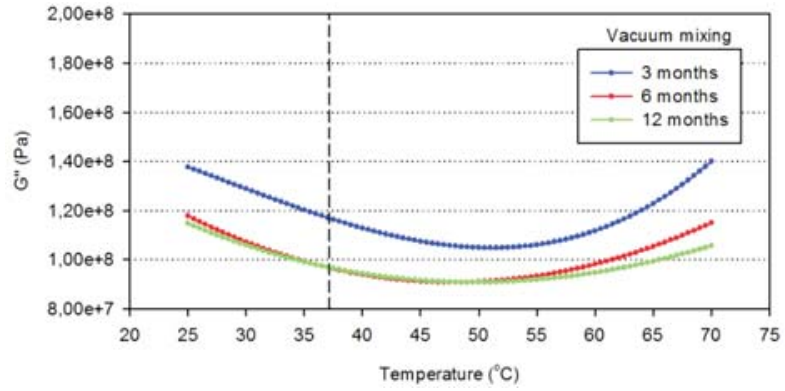

Fig. $4 G^{\prime \prime}$ of vacuum-mixed samples

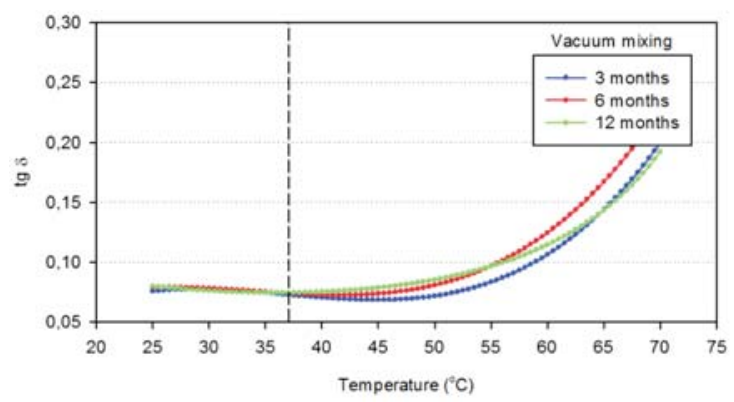

Fig. $6 \operatorname{tg} \delta$ of vacuum-mixed samples

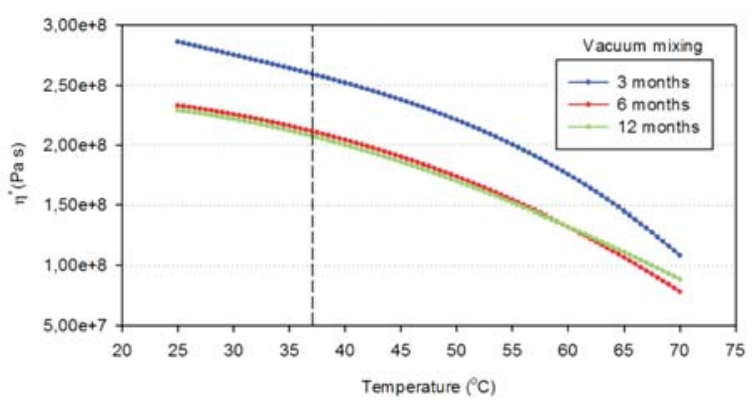

Fig. $8 \eta *$ of vacuum-mixed samples 
The results of rheological measurements are shown in Figs. 1 - 8. The temperature of $37^{\circ} \mathrm{C}$ which corresponds to the body temperature is marked with dashed line.

The results obtained show that after the hardening process of cement it is still subjected to continuous structural changes for both techniques of mixing. Differences in courses of the obtained characteristics mean that the sensitivity of the cements to temperature changes by the time of exposition and vary for each mixing technique. Hand-mixed cements are more sensitive to temperature than the ones mixed in vacuum. This phenomenon springs from the fact that the structure of cements and their properties were influenced by the mixing technique.

During the exposition in given environment (air) the cement was in direct contact with air humidity. For different concentration of water molecules in the air and in the structure of cement gradient controlled diffusion occurred. Diffused molecules of water to bone cement act as plasticizers and influence its physical and mechanical properties [10]. It is commonly known that cement mixing at reduced pressure minimizes the number of ineligible pores in its structure [1]. Thus, the density of cement is higher and free volume between the molecules is lower. Changes in physical and mechanical properties of vacuum-mixed cement are then less influenced by the environment in which the cement is stored, in this case by the diffused molecules of water. This claim is confirmed by relatively unchanged values of parameters for vacuum mixed cements after 6 months of exposition.

Our attention should be further focused on the parameters measured at body temperature, e. g. at $37^{\circ} \mathrm{C}$. After 3 months of exposition the storage modulus $G^{\prime}$, the loss modulus $G^{\prime \prime}$ and also the complex viscosity $\eta^{*}$ decreased for both techniques of mixing. This phenomenon could be caused by higher mobility of polymer chains rested in plasticizing effect of diffused water from the surrounding environment. After next 3 months of exposition only small changes were registered for vacuum mixed cements but the changes in hand-mixed ones remained to continue. In term of energy dissipation which is presented by the damping factor $\operatorname{tg} \delta$, no changes occurred in vacuum-mixed cements during the monitored period. In other study we also registered time-dependent changes in bone cement tested by indentation measurements of microhardness, elastic modulus and creep.

Described processes are much faster in vivo where bone cement is directly washed with body fluids and for increased temperature as well. Thus, the in vivo behaviour of bone cement forms a comprehensive problem which also includes the bilateral diffusion of molecules of residual monomer and of body fluids. So, the changes occurred in the cement in vivo may originate from different reasons. On the other hand, these changes may be partially influenced by later polymerization of the confined monomer in the structure of cement and by other chemical processes activated e. g. by oxidation. The effect of structural changes on mechanical properties of acrylic bone cement was also shown by Hailey et al. [11]. They showed that the individual storage media and temperatures have significantly different effects on its behaviour.

\section{Conclusions}

Performed rheological measurements show that in bone cement SmartSet ${ }^{\circledR}$ HV structural changes over the time can be reported. These changes occurred without previous functional loading of the cement when it was stored in a wet environment. The measures of these changes partially depend on the structure of material influenced by a mixing method. Results obtained after different periods of testing were caused by ongoing polymerization, by diffusion of water molecules to structure of the cement as well as by other chemical changes. The mentioned results suggest a need for standardization of storage conditions of acrylic bone cements. Later effect of cyclic stresses in vivo e. g. during walking could influence the mechanical properties of the cement over the time as well and the changes may affect stress distribution in the bone-cementprosthesis complex.

\section{Acknowledgements}

This research has been supported by the Scientific Grant Agency of the Ministry of Education of the Slovak Republic and Slovak Academy of Sciences, grant No. 1/0603/08. This support is gratefully acknowledged.

\section{References}

[1] LIPTAKOVA, T., LELOVICS, H., NECAS, L.: Variations of Temperature of Acrylic Bone Cements Prepared by Hand and Vacuum Mixing During their Polymerization. In: Acta of Bioengineering and Biomechanics, ISSN 1509-409X, 2009, Vol. 11, No. 3, p. 47-51.

[2] ORR, J.F., DUNNE, N.J., QUINN, J.C.: Shrinkage Stresses in Bone Cement. In: Biomaterials. ISSN 0142-9612, 2003, vol. 24, No. 17, pp. 2933-2940.

[3] LELOVICS, H., LIPTAKOVA, T.: Comparison of Surface Temperatures of Acrylic Bone Cements During Polymerization After Different Techniques of Mixing. In: $26^{\text {th }}$ Danubia-Adria Symposium on Experimental Methods in Solid Mechanics. Leoben, 2009. ISBN 978-3-902544-02-5, pp. 135-136.

[4] FARRAR, D.F., ROSE, J.: Rheological Properties of PMMA Bone Cements During Curing. In: Biomaterials. ISSN 0142-9612, 2001, vol. 22, no. 22, pp. 3005-3013.

[5] MEZGER, T.G.: The Rheology Handbook. $2^{\text {nd }}$ ed. Hannover: Vincentz Network, 2006. 299 p. ISBN: 3-87870-174-8. 
[6] NICHOLAS, M.K.D. et al: Analysis of Rheological Properties of Bone Cements. In: Journal of Materials Science: Materials in medicine. ISSN 0957-4530, 2007, Vol. 18, No. 7, pp. 1407-1412.

[7] POSTAWA, P., SZAREK, A.: Analysis of Changes in Bone Cement Damping Factor and its Effect on Bone Load. In: Journal of Achievements in Materials and Manufacturing Engineering. ISSN 1734-8412, 2007, Vol. 23, No. 1, pp. 35-38.

[8] ASTM D5279: Standard Test Method for Plastics: Dynamic Mechanical Properties In Torsion, 2008.

[9] ISO 6721: Plastics - Determination of Dynamic Mechanical Properties. 1999.

[10] NOTTROTT, M. et al: Time Dependent Mechanical Properties of Bone Cement. An in Vitro Study Over one Year. In: Journal of Biomedical Materials Research - Applied Biomaterials. ISSN 1552-4973, 2007, Vol. 83, No. 2, pp. 416-421.

[11] HAILEY, J.L., TURNER, I.G., MILES, A.W.: An in Vitro Study of the Effect of Environment and Storage Time on the Fracture Properties of Bone Cement. In: Clinical Materials. ISSN 0267-6605, 1994, Vol. 16, No. 4, pp. 211-216. 